\title{
والموأتهرات
}

\section{استراتيجية روسيا الأوروآسيوية}
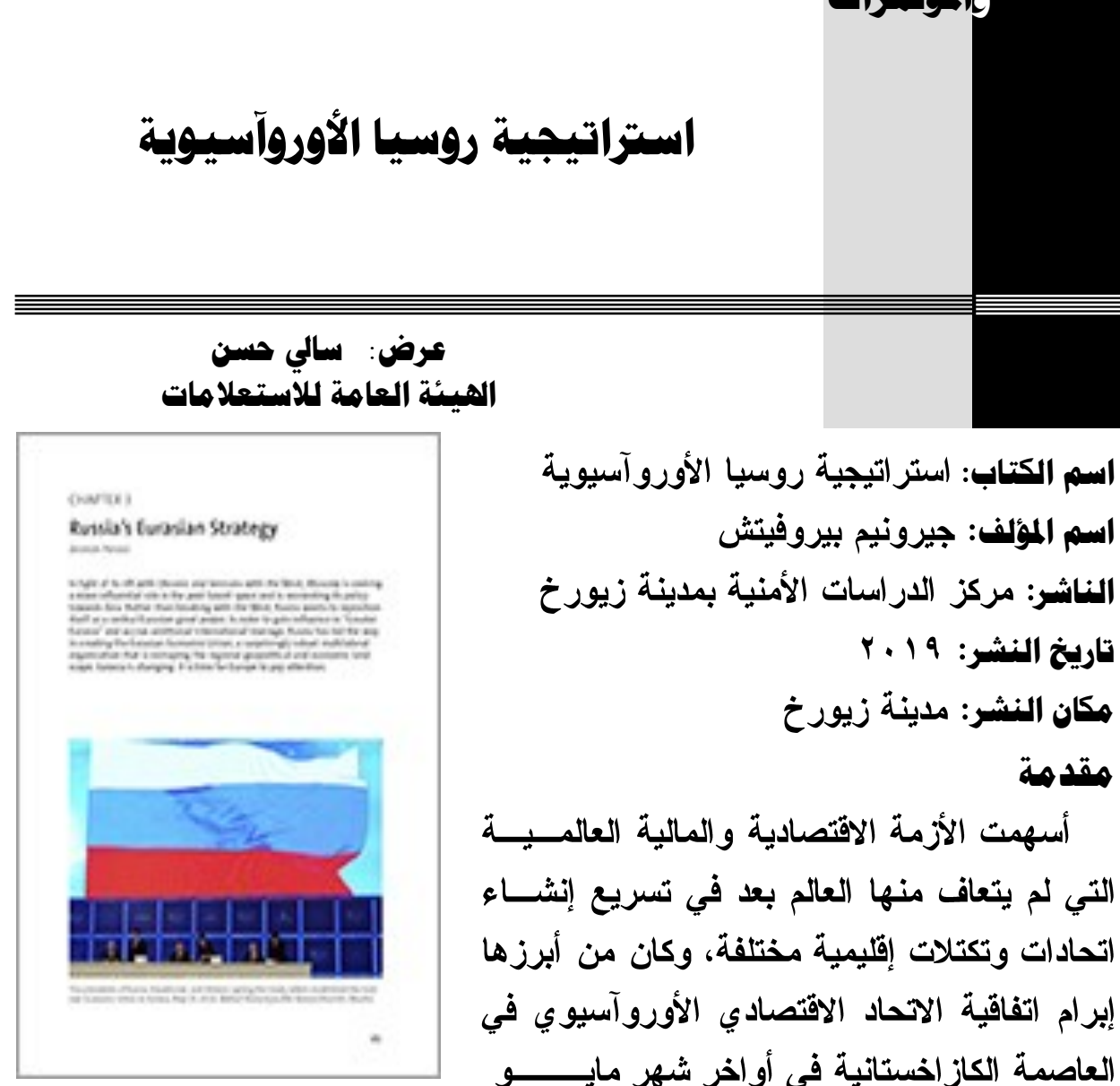

اسم الكتاب: استراتيجية روسيا الأوروآسيوية

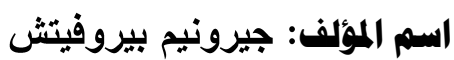

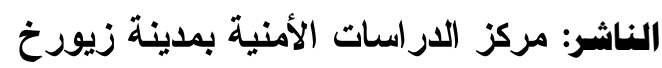

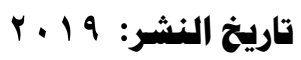
هوان النشر: مدينة زيورخ هقدهة

أسهمت الأزمة الاقتصادية و المالية العالمــــــة

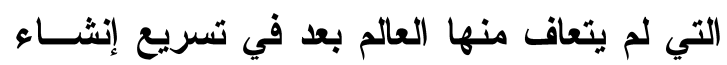
اتحادات وتكتلات إقليمية مختلفة، وكان من أبرزها

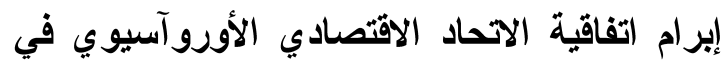

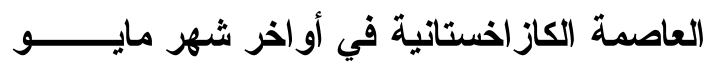

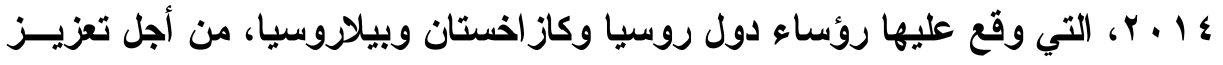

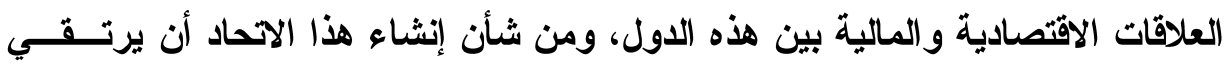

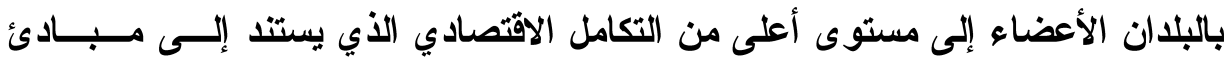

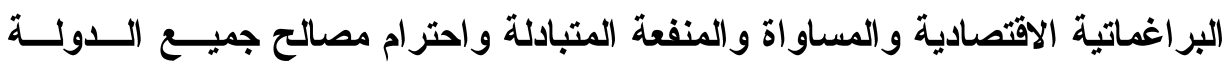

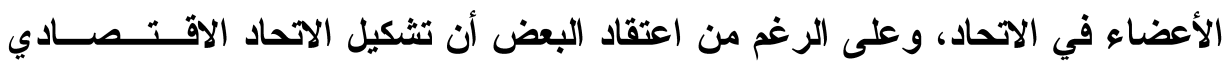

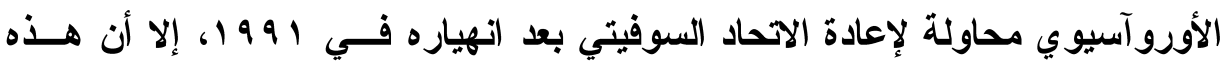
الفكرة بعيدة إلى حد كبير، حيث تفرض التطورات في الوقت الرهن قوادئ الاعد جديدة للعب

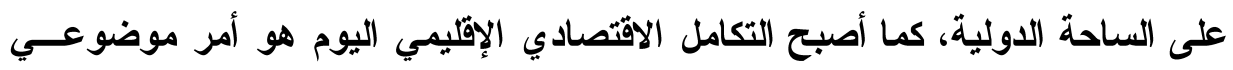




\section{(4)}

ومطلوب في ظل ظروف العولمة وزيادة التنافسية العالمية ما يدفع نحو ظهور وتعزيز اتحادات إقليمية تتعاون فيما بينها للاستجابة بشكل فعال للتحديات الاقتصادية الناشئةً.

\section{التهديات التي تواجه روسيا}

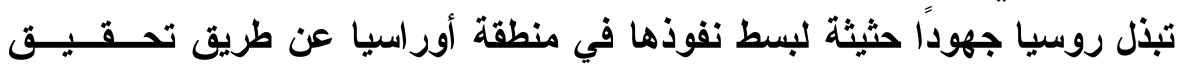

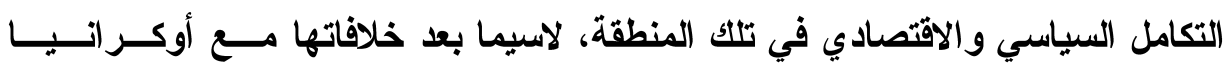

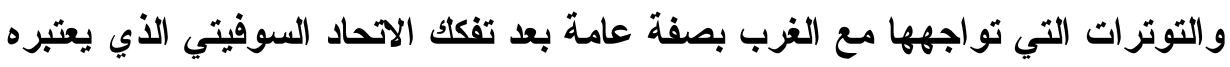

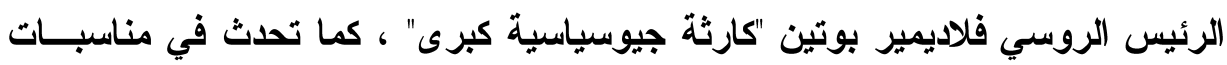

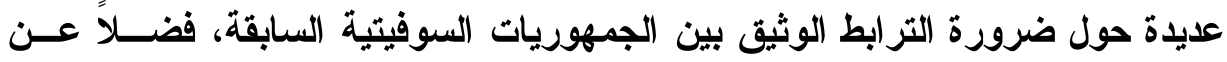

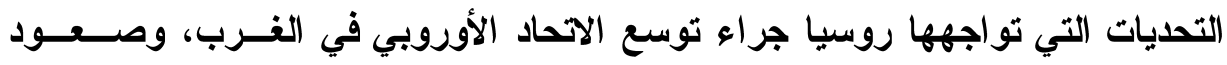

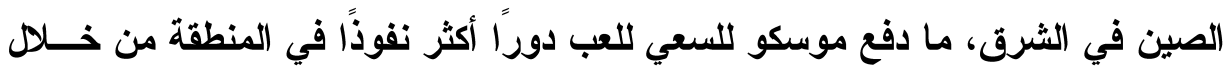

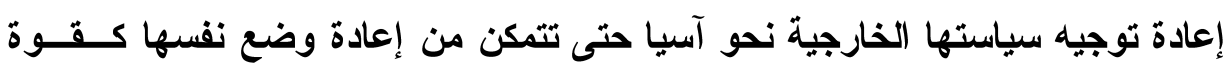

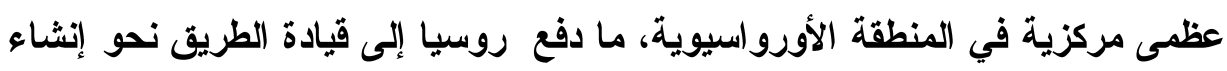

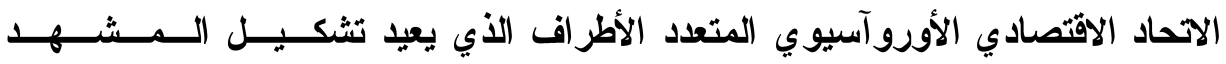
الجيوسياسي والاقتصادي الإقليمي.

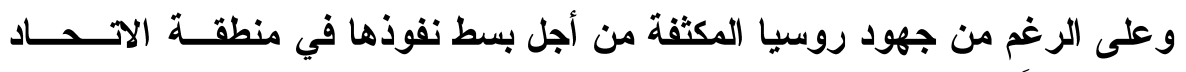

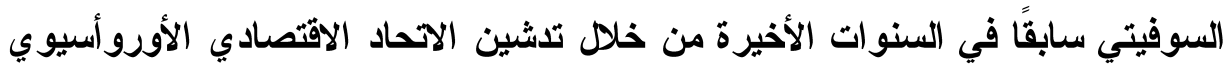

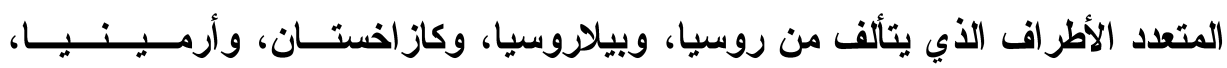

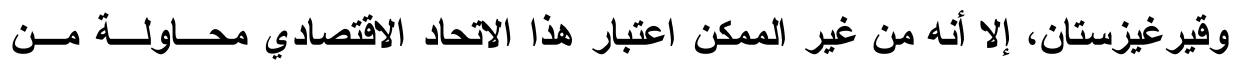

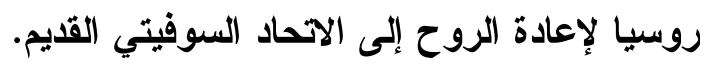

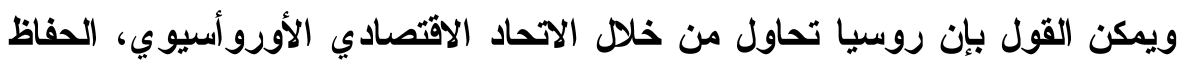

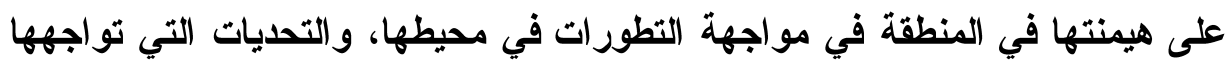

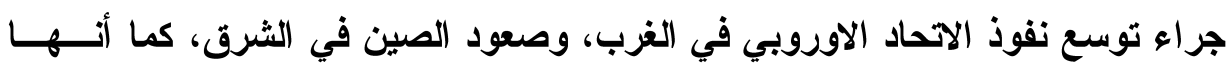

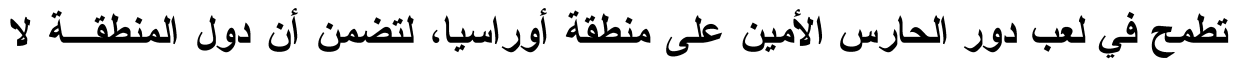

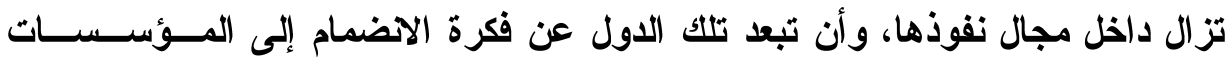

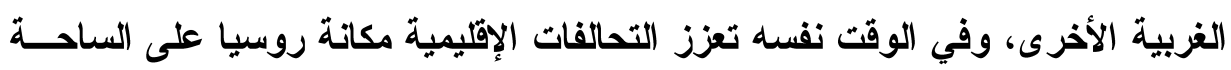




\section{敦}

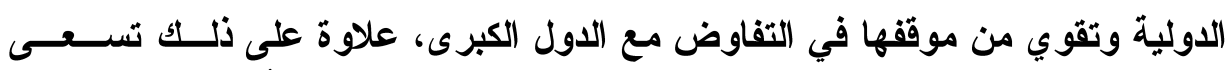

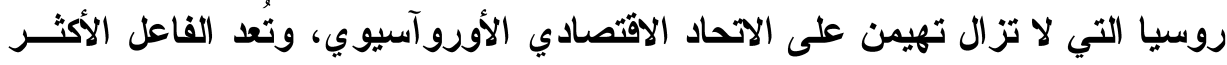

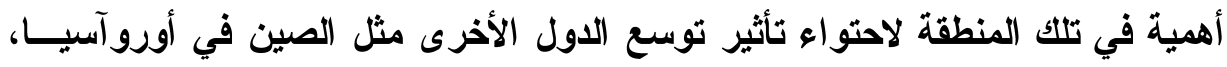

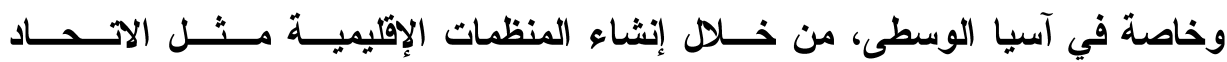

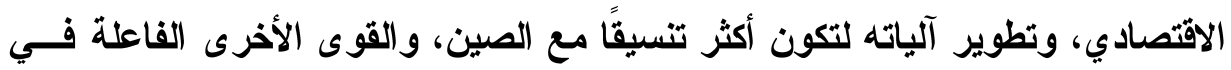
المنطقة.

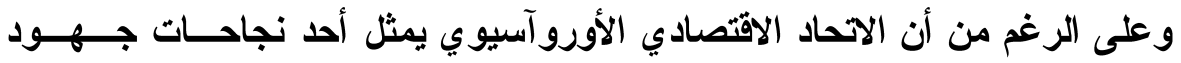

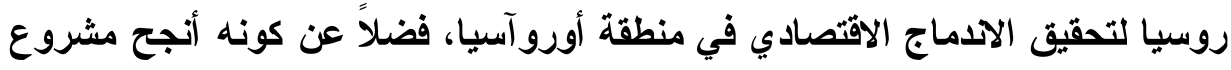
للتكامل الإقليمي منذ انهيار الاتحاد السوفيتي في عام 991 1، إلا أن هيمنة روسيا على الألى

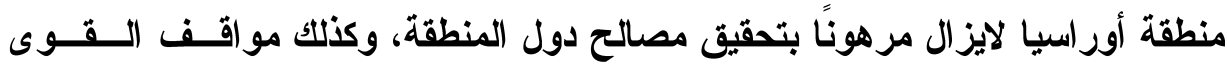
الخارجية، ففي حين ترتبط بعض دول في المنطقة ميع روسيا بشكل وثيق فــي إطـار الاتحاد الاقتصادي الأوروأسيوي EAEU وغيره من المنظمات الإقليمية الأخــرى، إلإنيات

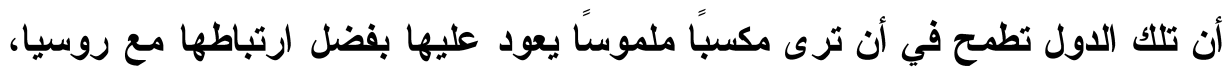

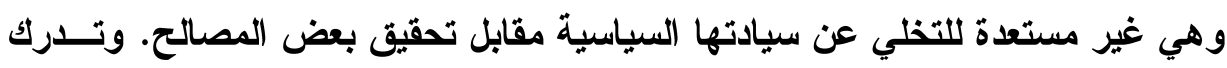

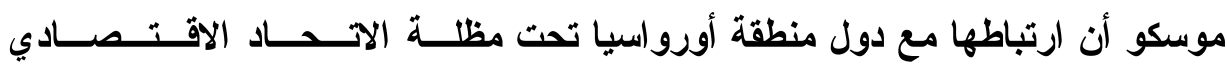
الأوروآسيوي قد يأتي بنتائج عكسية، إذ تنتظر الدول الأعضاء في هذا التجمع أن تقود التهائ

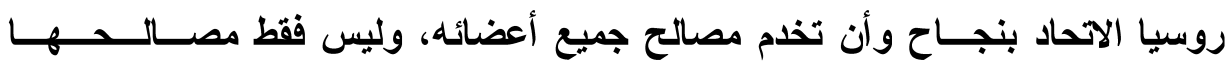
الخاصة.

\section{تهقيق التكاهل المتعدد الأطراف}

اتخذت روسيا عدد من الخطوات بعد انهيار الاتحاد السوفيتي من شأنها أن تحافـظ

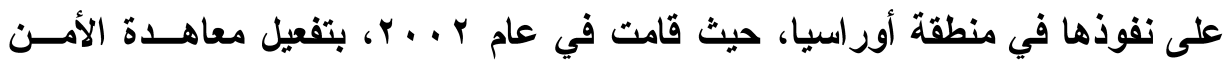

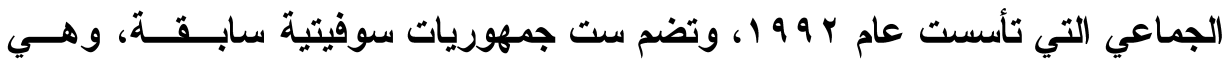

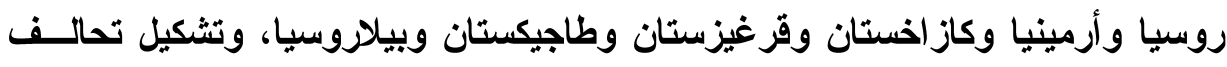

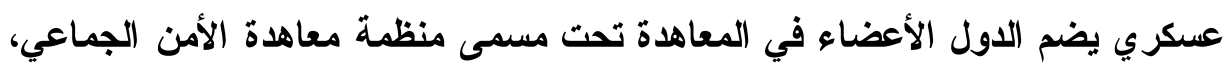
وعلى الرغم من أن هذه المنظمة لم تعمل بكامل فعاليتها حتى الوقت الر اهن، إلا أنهــا 


\section{6}

تمبلك آليات تؤهلها لأن تصير تحالفًا أمنيًا متكامناً شبيه بحلف الناتو، إذ يلتزم أعضائها

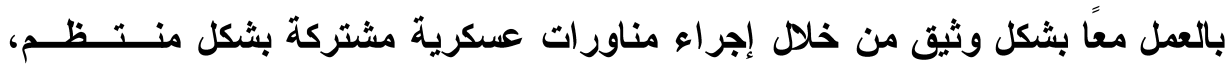

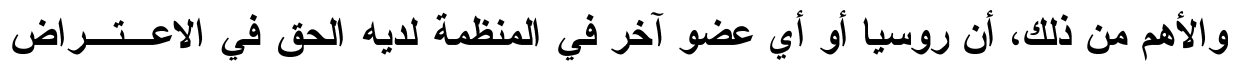

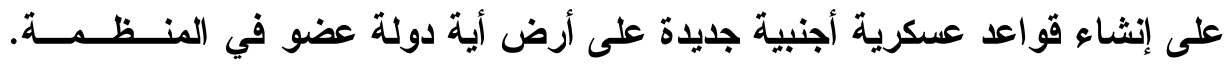

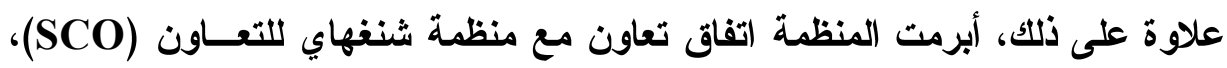

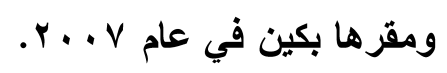

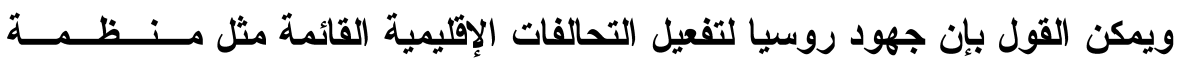

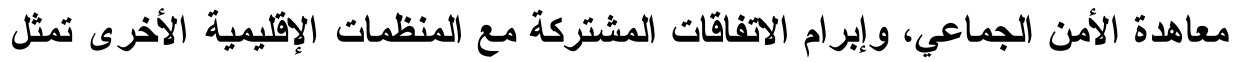

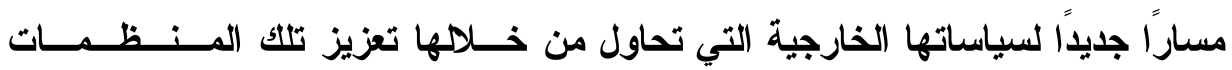
الإقليمية حتى تتمكن من بسط نفوذها، وبناء علاقات قوية مع الدول و والمـــــــــــــــات

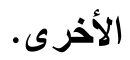

\section{هن أوروبا الكبرى إلى أوراسيا الكبرى (الكي}

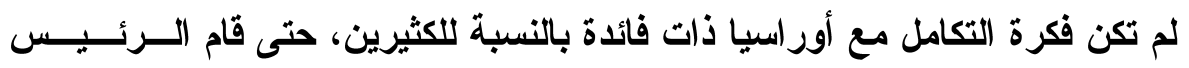

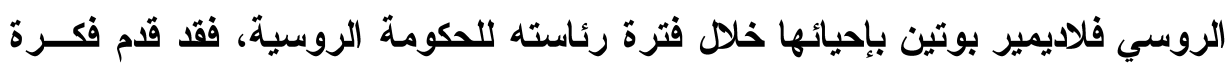

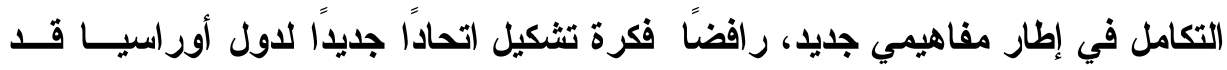

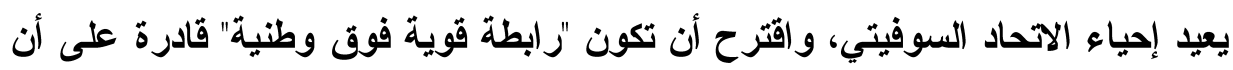

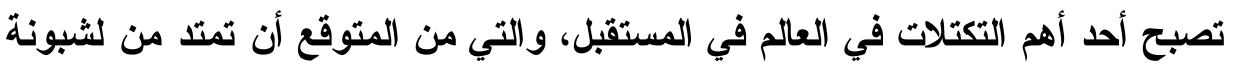

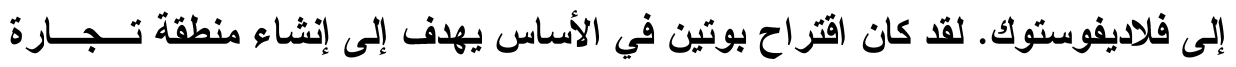

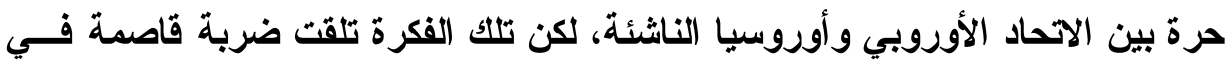

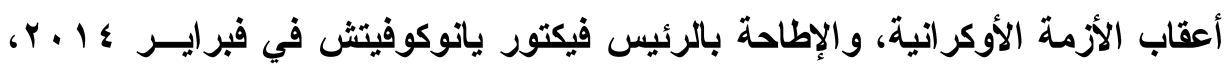

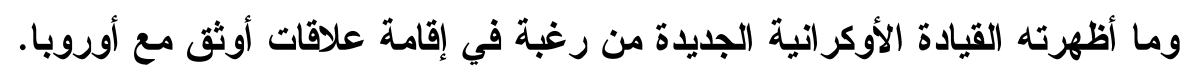

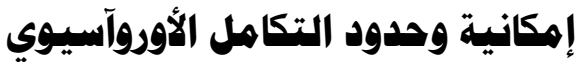

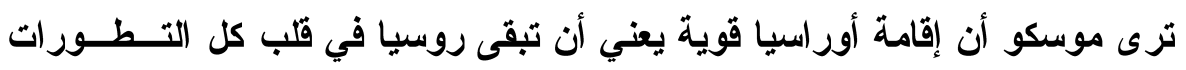

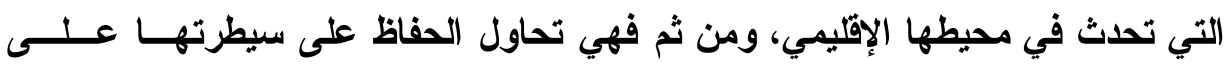

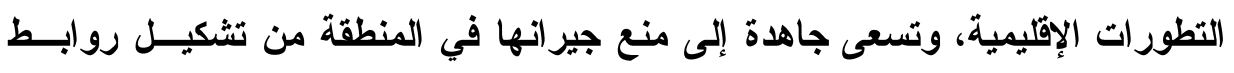




\section{(6)}

وعلاقات تجارية وسياسية مستقلة من خلال تعميق العلاقات ذات المنافع المتبادلة على

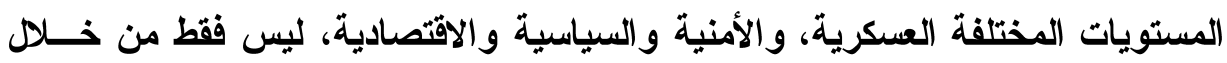
الاتحاد الاقتصادي الأوروآسيوي، ولكنه الأداة الأهم في الوقت الراهية واهن لتعزيز التحالفات

الإقليمية وضمان استمرار الهيمنة الروسية.

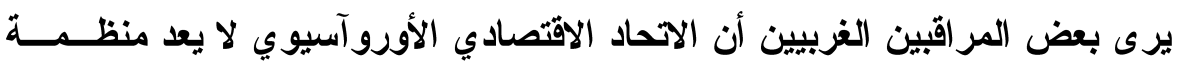

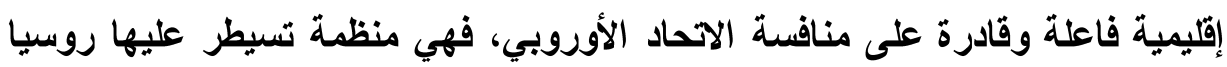
وتضم مجموعة من الاول التي من الممكن أن تثوافق مع سياسة بروكسل إذا اتيحست

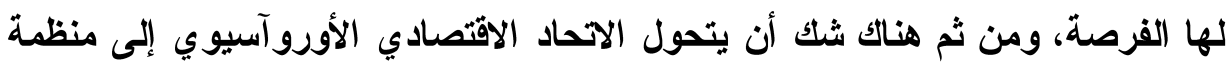

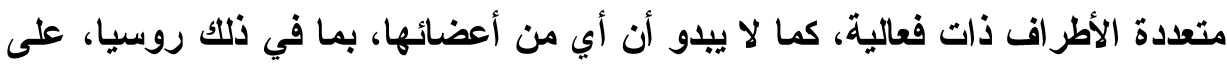
استعداد لتحويلها لمنظمة فوق الوطنية، كما يشك آخرون في أن المنظمة، التي تسيطر عليها دول قوية، سوف تحقق الكثير من التكامل والأدماج الحقيقي، وأن تطيح بالقيود الا اخلية المفروضة على حركة التجارة ونقل البضائع والأشخاص وغيرها من الخدمات

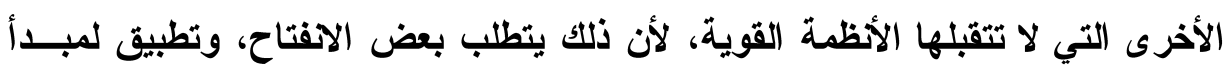

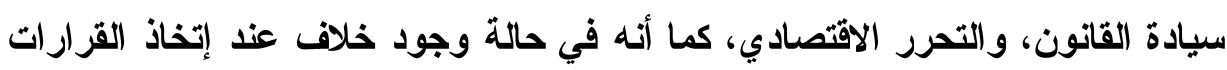

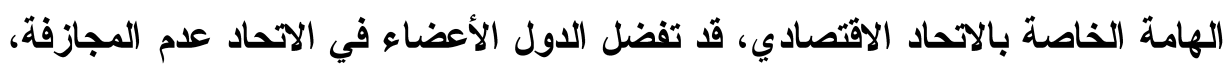

$$
\text { و التمسك بالقرارات التي تتخذها حكوماتها. }
$$

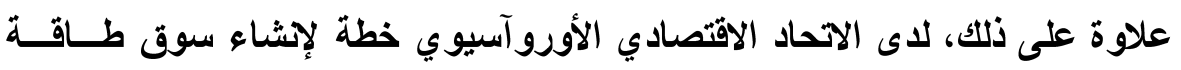

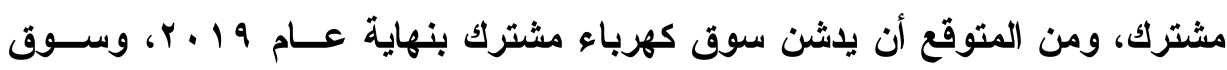

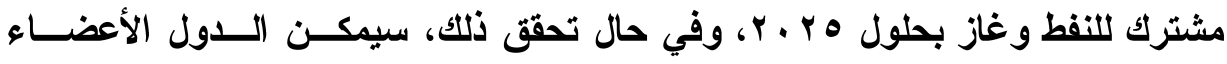
للاتحاد من الوصول غير المحدود إلى شبكات الطاقة. أيضًا يخطط الاتحاد لإزالة جميع

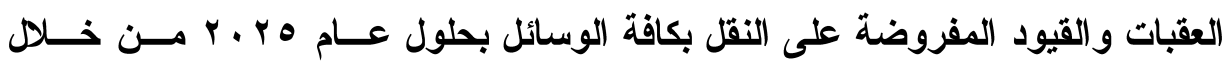
إنشاء شبكة من وسائل النقل المشتركة من خلال إنشاء الطرق، والمواصلات البحرية،

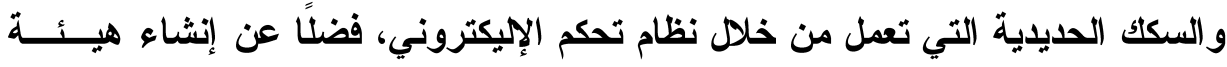

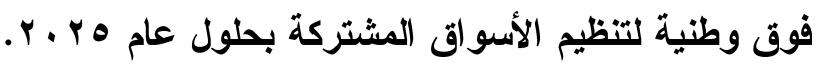




\section{التحدي الذي يواجه روسيا}

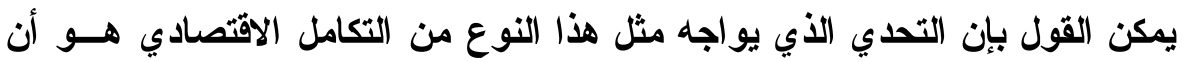

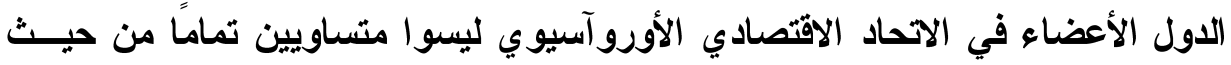

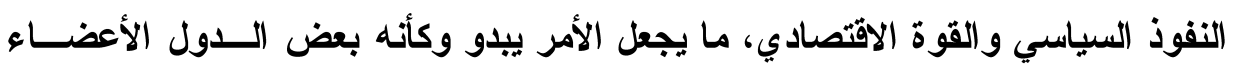

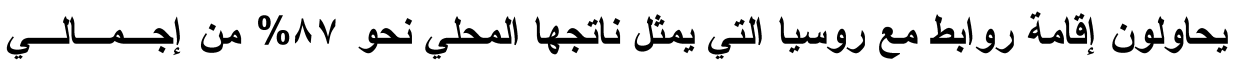

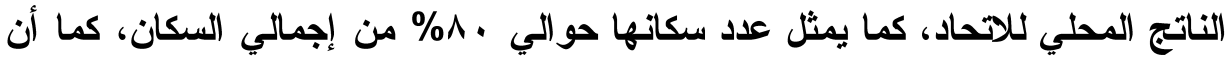

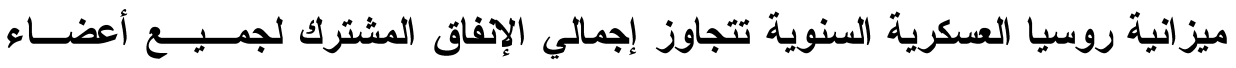

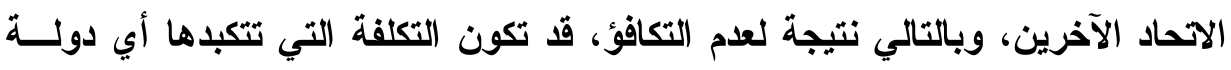

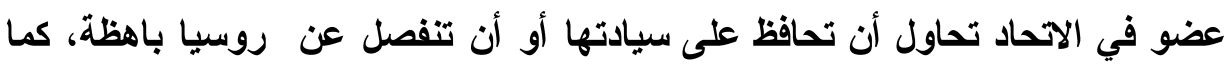

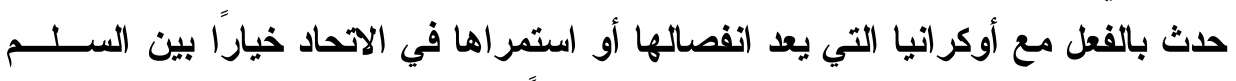

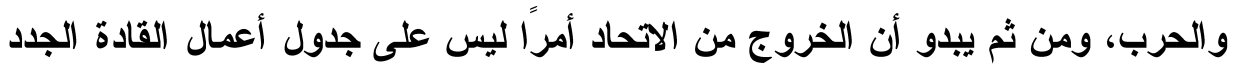

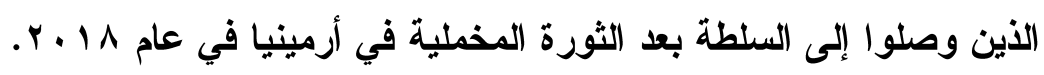

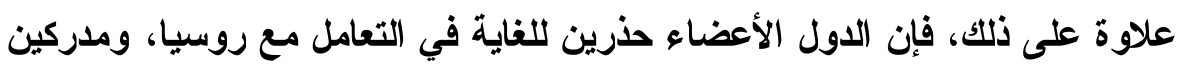

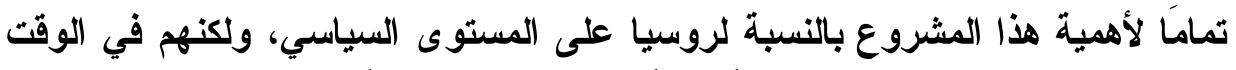

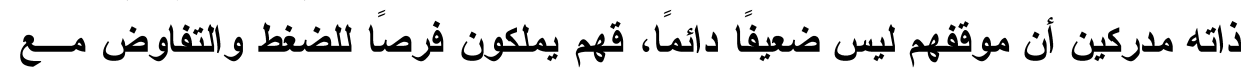

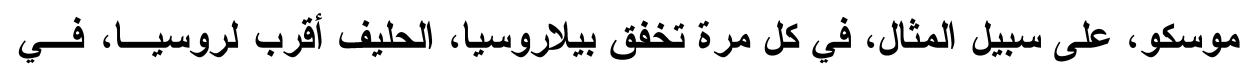

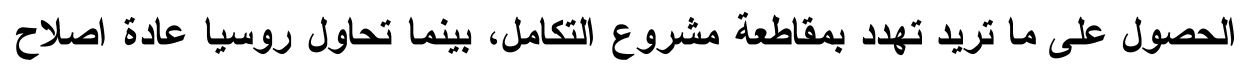

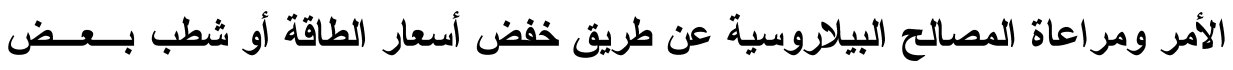

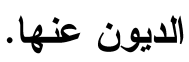
ولم تمنع الهيمنة الروسية على الاتحاد وحرصها على مثروع التكامل بـــــن دول

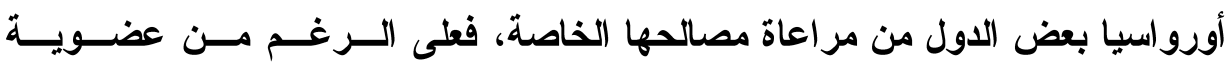

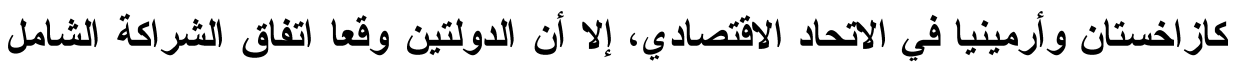

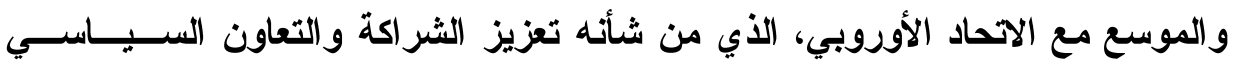

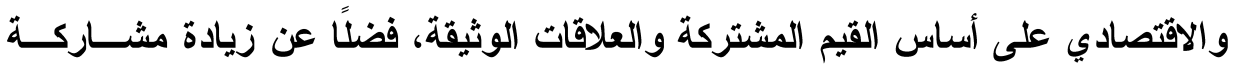

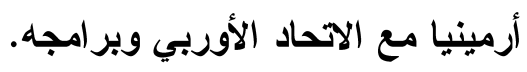

العدد الخامس - 9 (

rV. 


\section{6}

وعلى جاتب أخر، نجد روسيا أيضا، في بعض الأحيان، تقدم مصالحها الاقتصاديــة على تعزيز الاتحاد، فعندما رفض أعضاء الاتحاد اتباع سياسة روسيا ومقاطعة الاتحاد

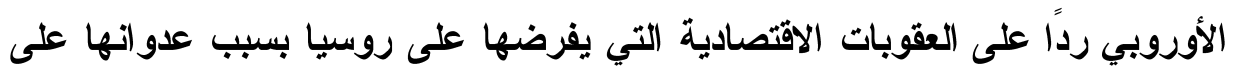
أوكرانيا في عام \& 1 ـ r، كذلك لم يلعموا العقوبات التي تفرضها روسيا على تركيا منذ

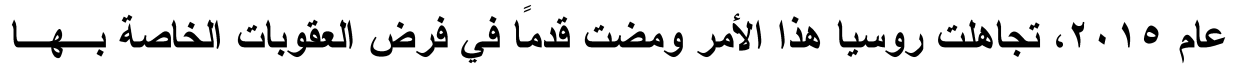
على الغرب، وفي وقت لاحق على البضائع التركية، فروسيا تميل إلى تجاهل القـيــود

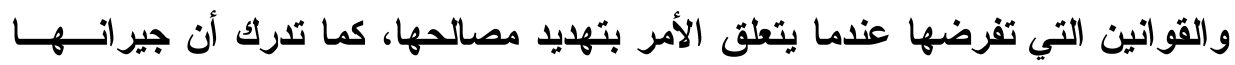
أصبحوا أكثر حساسية لأي ضغط سياسي أو اقتصادي يمكن أن تمارسه عليهم خاصــة بعد الأزمة مع أوكر انيا. على الرغم من أنه من الواضح أن روسيا هي أقوى عضو الأنا، الاتحاد، وأكثرهم تأثيرًا

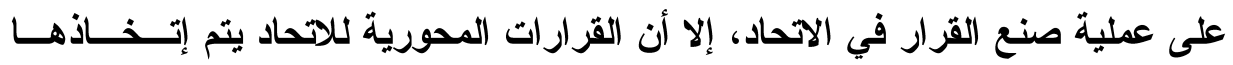

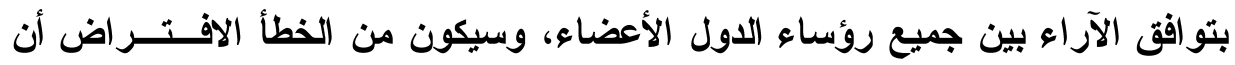

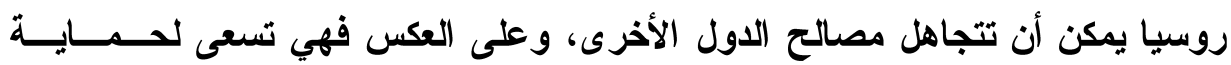

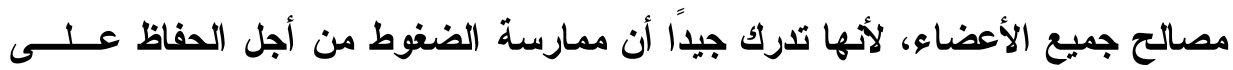

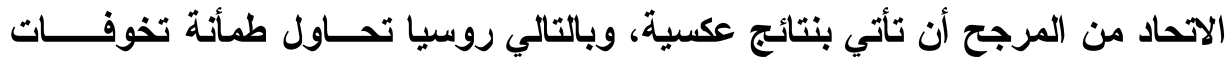

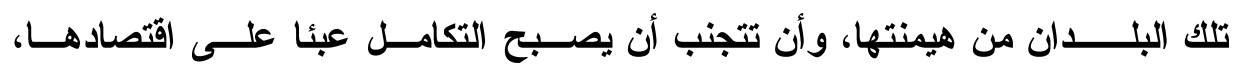

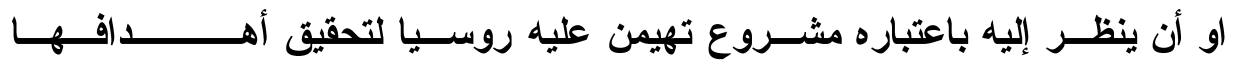

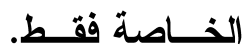

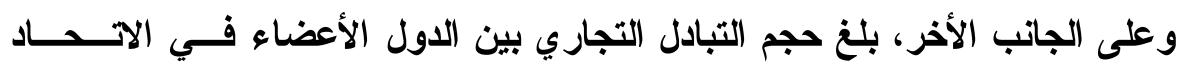

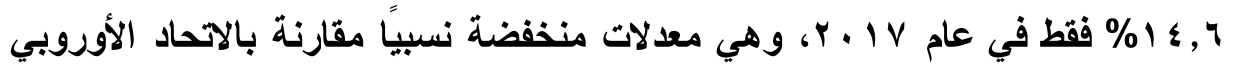

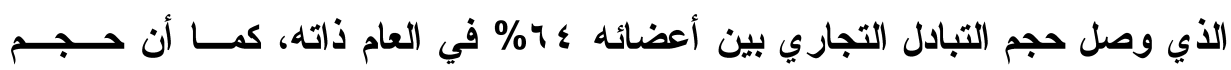
التجارة الخارجية لمعظم الدول الأعضاء في الاتحاد أعلى من تلاتك المعدلات بشكل كبير،

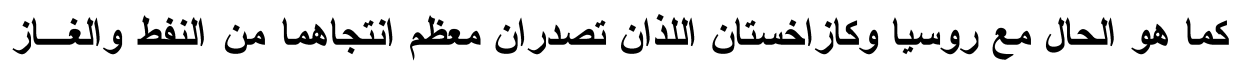
إلى خارج دول الاتحاد. 


\section{الاتحاد الاقتصادي الأوروأسيوي والصين}

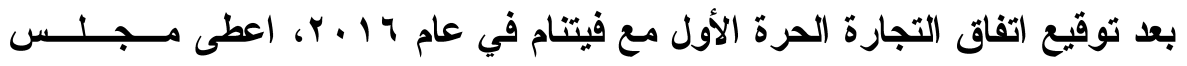

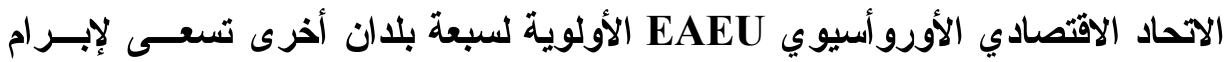

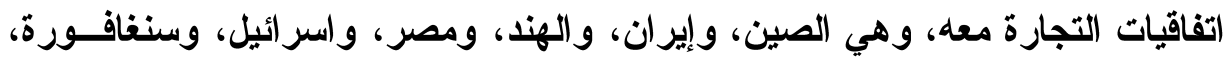

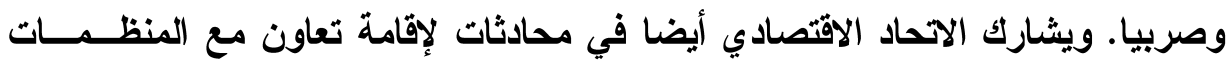
الدولية، بما في ذلك منتدى التعاون الاقتصادي لدول آسيا والمحيط الهادئ (روسـيـيـات

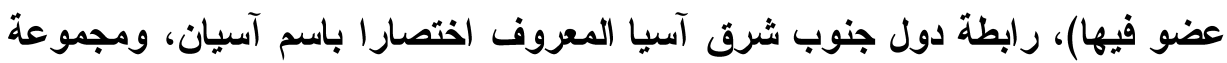
دول الأديز، والسوق المشتركة الجنوبية، وكذلك العديد من المنظمات الدولية الآخرين،

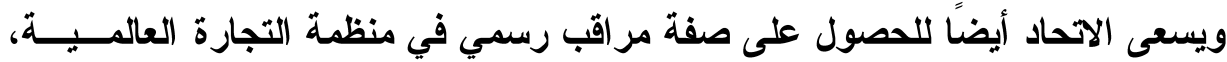
لكنه فثل حتى الآن في إقامة علاقات رسمية مع الإقيات الإتحاد الأوربي.

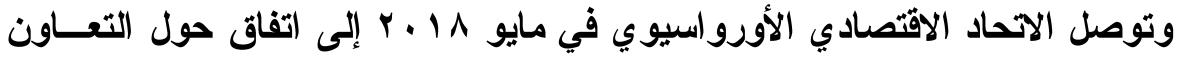
الاقتصادي والتجاري مع الصين، وقد يكون للاتفاق مع الصين ذو الهائ الهية كبيرة، خاصة الهان

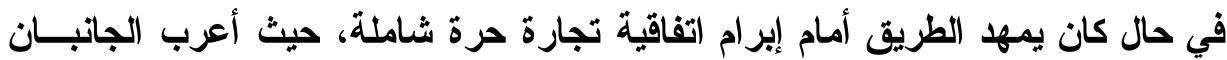

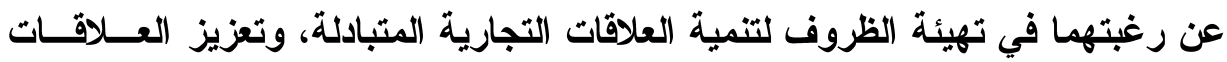

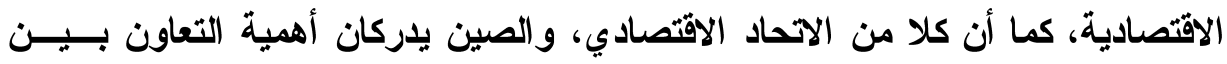

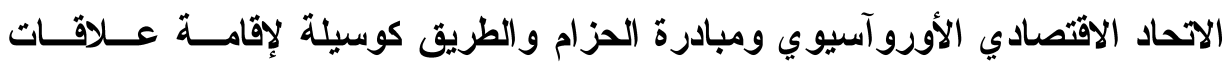
تجارية قوية ومستقرة في المنطقة.

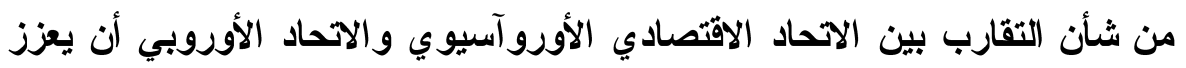

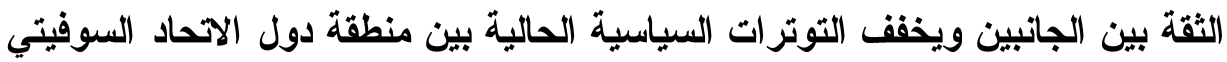

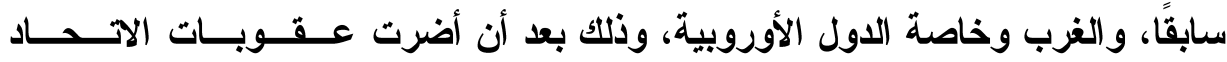

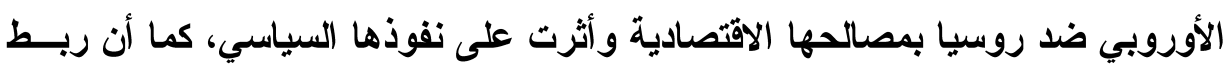

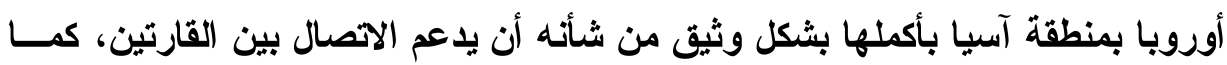

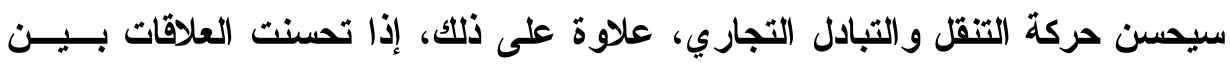

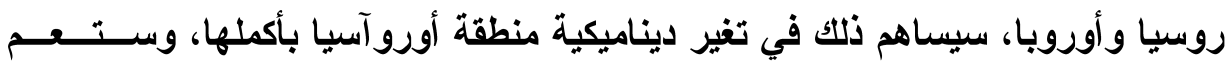

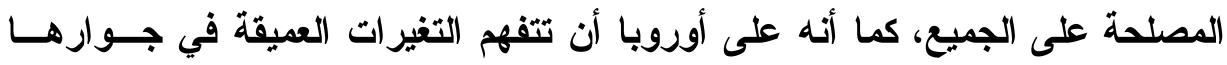
الثرقي وأن تعيد النظر في موقفها تجاه الآحاد الأوروآسيوي.

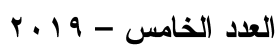

rVY 